\title{
Pro-Environmental Workplace Intention Behaviour in the Malaysian Public Organization
}

\author{
Norjumaaton Fazhani Razak ${ }^{1}$ \& Mohamad Fazli Sabri ${ }^{1}$ \\ ${ }^{1}$ Faculty of Human Ecology, University Putra Malaysia, Malaysia \\ Correspondence: Norjumaaton Fazhani Razak, Faculty of Human Ecology, University Putra Malaysia, Malaysia. \\ Tel: 60-01-6222-0354. E-mail: juma.hani@gmail.com
}

Received: February 10, 2019

Accepted: March 5, 2019 Online Published: March 29, 2019

doi:10.5539/ass.v15n4p60

URL: https://doi.org/10.5539/ass.v15n4p60

\begin{abstract}
This study utilizes Ajzen's Theory of Planned Behaviour as its theoretical framework to extend the previous literature on pro-environmental workplace intention-behaviour in the organization. Findings indicated that all factors (attitude, subjective norms and perceived behavioural control) have a significant positive influence on pro-environmental workplace intention-behaviour. This study contributes to body of research and extends our understanding of the pro-environmental workplace intention-behaviour in the Malaysian public sector and identifying the most influences factor of pro-environmental workplace intention-behaviour. It is essential for public sector employee to have positive environmental workplace behaviour to support government policy implementation for the green organization.
\end{abstract}

Keywords: pro-environmental workplace behaviour, sustainability, environmental management, HRM practices

\section{Introduction}

\subsection{Pro-environmental Behaviour in the Workplace}

One of the most critical problems faced in our society is environmental problems. Various researchers are in unison agreed that issues such as this are severe and human-made (Oreskes, 2005). Thorough understanding had to be obtained to change human behaviour. Previous studies have provided literature on the pro-environmental behaviours at the household or social setting. Within the organization setting, there is minimal understanding of pro-environmental behaviours found among studies despite being one of the major contributors to the environmental problems.

According to Blok et al. (2015), organizational behaviour is not being investigated thoroughly within the field of organizational behaviour. Findings have shown that employees dedicated a third of their days in the workplaces. Thus, the reduction of negative impact on the environment is at least expected due to their pro-environmental behaviour. Hence, the focus of this study that is on the pro-environmental intention-behaviour of employee and factors that have an impact on pro-environmental intention-behaviour of an employee in the workplace.

This study had selected an employee from a public organization in Malaysia because since green growth will be one of the major focus in the 11th Malaysia Plan 2016-2020 for sustainability in socio-economic development. To pursue a green growth objective, one of the strategies is a green organization implementation to a public organization through employee behavioural change. This study has to identify the main factors (attitude, social norms and perceived behaviour control) which impact on pro-environmental intention-behaviour of an employee in the workplace. However, this was not yet investigated in the Malaysian public organization context. Thus, to fill this gap of empirical knowledge, the following research question is aimed to bridge the gap by asking: What factors determine the most significant influences of pro-environmental workplace intention-behaviour by an employee in public organization.

The research question is concerned with the role of individual employees might play through engaging in pro-environmental behaviours in the workplace. Pro-environmental workplace intention depends on the determinants of TPB which may differ significantly due to the differences of environmental setting, different cultures and countries or regions which then makes it harder to generalize the research results. Therefore, this justifies an empirical research study of Malaysian employee's attitude, social norms and perceived behaviour control about their intention to encourage pro-environmental behaviour in public organization. Hence, this will 
increase the present knowledge in terms of pro-environmental behaviour in workplaces in Malaysia especially in developing countries and their context.

The main objective of this study is to identify the most influencing factor of pro-environmental workplace behavioural intention using the Theory of Planned Behaviour (Ajzen, 1991). Etzion (2007) stated that most research in sustainability in an organization has primary examined the strategic, economic and performance related to an implication of sustainable business practices and on stakeholder perceptions without much consideration of the role that individual might play through engaging pro-environmental behaviour in the workplace. Many pieces of research on sustainable behaviour had focused on individual behaviour in household and community but very few considered pro-environmental behavioural in different environment such as the workplace. There might be a significant impact on the environment due to the pro-environmental behavioural at the workplace because most employees spend there at least eight hours at the workplace. Most common pro-environmentally behaviour in the workplace performed by employees is recycling, conserving energy and water, and reduce waste by reusing materials. Pro-environmental behaviour in the workplace can have a significant impact on the organization cost saving. For example, when employees turn off the lights and equipment not in use and printing document both sides of the paper can cumulatively result in cost saving as a whole. According to Theory of Planned Behaviour (Ajzen, 1991), attitude, social norms and perceived behaviour control are antecedent of intention-behaviour that will predict the actual behaviour (Fielding, McDonald, \& Louis, 2008; Maki \& Rothman, 2017). Therefore, an understanding of the factors related to employee intention behaviours in the workplace can help an organization to enable pro-environmental behaviours among employees because there is scarce knowledge of environmental behaviour at work which results to intention-behaviour in the workplace. It is vital to keep this understanding of motivation in pro-environmental behaviour as it has been found to significantly reduce environmental problems.

\subsection{Theoretical Background}

Theory of Planned Behaviour (Ajzen, 1991) is a theoretical framework commonly used to comprehend the human behaviour which explains motivation predictors of behaviour during certain situations. Motivational factors such as attitude towards the behaviour and subjective norm will form the individual's intention to perform a specific behaviour. In cases where the person has control (perceived behaviour control), a behaviour may occur due to the intention that emerged in the person. Thus, this study looks at perceived behavioural control as a motivator of intention, which is expected with intention, directly impacts peoples' behaviour (Ajzen, 1991). The presence of a realistic perception of control of the situation, it would increase the predictive power of perceived behavioural control on behaviour (Ajzen, 1991). In this model, subjective norm and perceived behavioural control are defined as independent variables and as for the dependent variables would be intention and behaviour. Additionally, it is well known that TPB is a widely used theory in the field of environmental studies (Nye \& Hargreaves, 2010). Hence, this study applies The Theory of Planned Behaviour (TPB) in pro-environmental intention-behaviour in public organization in Malaysia.

Generally, a pro-environmental behaviour is defined as to intentionally work towards minimization of the one's action that may impact negatively on the environment. A person's permission initiated pro-environmental behaviour as observed by Stern (2000). On the other hand, Bissing-Olson, Iyer, Fielding and Zacher (2012) defined that pro-environmental behaviour is of which employees commit and complete their tasks at hand in their environment. Employee pro-environmental behaviour was also mentioned as an extensive set of environmentally responsible activities (Graves, Sarkis, \& Zhu, 2013).

Therefore, very limited knowledge about environmental behaviour at a workplace and what factors that could motivate specific behaviour. Thus, pro-environmental behaviour at a workplace is important to study because it leads to a substantial diminishing of environmental problems (Evans, Russel, Hill, \& Fielding, 2012).

According to the Theory of Planned Behaviour (Ajzen, 1991), it is expected that attitude towards an environmental issue, subjective norm and perceived behaviour control will have a positive relationship towards pro-environmental behaviour intention. The Theory of Planned Behaviour (TPB) has been used in several studies which investigate pro-environmental behaviour (Fielding et al., 2008; Greaves \& Zibarras, 2013; Lokhorst, Staats, \& Van Iterson, 2015; Mahmud \& Osman, 2010; Paillé, Amara, \& Halilem, 2018; Pothitou, Hanna, \& Chalvatzis, 2016; Ramayah, Lee, \& Mohamad, 2010; Tonglet, Phillips, \& Read, 2004; Tudor, Barr, \& Gilg, 2016; Turnbull Loverock, 2010; Young et al., 2015). Nonetheless, there is no conclusion of which factor weighed more in predicting pro-environmental behaviour as the findings differ from each case, hence reflects on the diversifies backgrounds of studies.

A study had reported that the strongest determinant of recycling intention is perceived behaviour control, while 
the social norm is the second strongest determinant. Meanwhile, it was reported by Tonglet et al. (2004) the strongest predictor of recycling intention and not significant predictor of intention are attitude and perceived behavioural control respectively. They also debated that it was due to the participants in their study were well versed in the subject of recycling in terms of experience and its satisfactory condition. Surprisingly, it was suggested when individuals possess low recycling abilities; their perceived behavioural control would significantly predict intention. On the contrary with the previous study, Ramayah et al., (2010) identified the factor that predicts pro-environmental behaviour are both subjective norm and attitude, while perceived behavioural control did not. There are apparent differences in determining the predictive power of subjective norm on intention (Chen \& Tung, 2010; Gao, Wang, Li, \& Li, 2017) who has reported a significant influence of subjective norm on intention, while other researchers (Karim Ghani, Rusli, Biak, \& Idris, 2013; Tonglet et al., 2004) found that subjective norm did not significantly predict recycling intention.

Hence, the literature shows that although factors in TPB can predict the behaviour intention, which factors most influencing to predict the behaviour still changeable from all the studies. So, it is important to study which factors influencing the pro-environmental factor in this study to understand the pro-environmental behaviour intention in a workplace in the Malaysia public organization context.

\subsection{Conceptual Framework and Hypotheses}

The research model used in this study, shown in Figure 1, is based on TPB. The intention of environmental workplace behaviour goes before the actual behaviour. The intention is usually entailed with future behaviour. Most of the time attitude is hypothesized to have a direct and positive relationship with behavioural intention. The relationship between perceived behavioural control and subjective norms is also postulated as a direct and positive relationship in this model. To examine the relationship between the independent variables (attitude, perceived behaviour control and subjective norm) and the dependent variable (behavioural intention in environmental workplace behaviour), three hypotheses were developed. Therefore, this study investigates whether there is a direct and positive relationship between attitude, perceived behavioural control, subjective norm and behavioural intention.

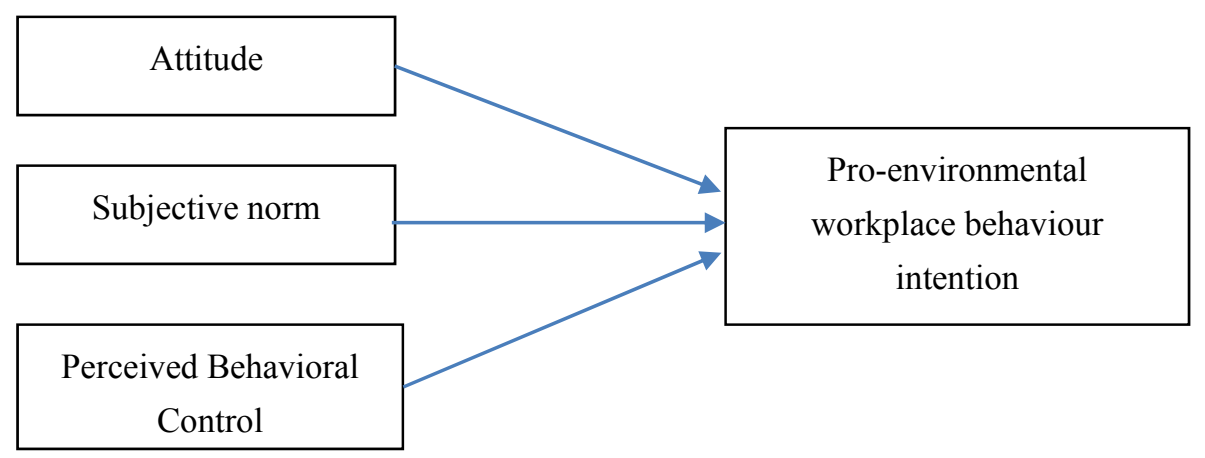

Figure 1. Conceptual framework

H1. There is a significant and positive relationship between attitude and behavioural intention to pro-environmental workplace.

Firstly, attitude is conjectured as an essential factor that affects most of our behaviour. Having the right attitude in the workplace would help in determining employee behaviour towards organizational activities. Hence, this study focuses on attitudes towards pro-environmental behavioural intention in the workplace. The definition of attitude is the act of evaluating people positively or negatively in regards to the behaviour in question. The rule of thumb to ensure a pro-environmental behaviour is that there must be an increase in positive the attitude and subjective norm concerning behaviour, and the stronger the perceived behavioural control. Naturally, there should be an individual's intention to perform the actual behaviour under consideration. Therefore, attitude is seen as a pivotal part to predict and describe human behaviour (Ajzen, 1991).

H2. There is a significant and positive relationship between subjective norm and behavioural intention to environmental workplace.

The predictor social factor (subjective norm) is seen as a perceived pressure from social circle to follow with the expectations to engage in behaviour as well as influence the intention of one to perform the behaviour or vice 
versa. Subjective norms in the workplace are the perceptions an individual has about the expectation may lead to performing a certain behaviour. In this case, if performing an environmentally friendly behaviour in the workplace is seen as positive behaviour which is also and socially desirable it would influence the individual to be more likely to perform an actual environmentally friendly behaviour in the workplace. Several studies (Ramayah et al., 2010; Robertson \& Barling, 2013) have shown that social factors have a positive association with pro-environmental behaviour. However, in this study, the subjective norm is the perceived pressure from social circle that influences employee choices to perform environmentally friendly behaviour in the workplace. By definition, the employees' decision to perform environmentally friendly behaviour is due to perceived social pressure as the subjective norm.

H3. There is a significant and positive relationship between perceived behaviour control and behavioural intention to pro-environmental workplace.

Ajzen (1991) stated that perceived behavioural control has explained the range to which a person is interested in engaging in the behaviour. The main two aspects of this are the aspect of behaviour control of the person and the evaluation of self on whether they can person the behaviour or not. They can be explained as "how much a person has control over behaviour' and 'how confident a person feels about being able to perform or not perform the behaviour. The more control an individual has to carry out environmentally friendly behaviour in the workplace, the higher the chance the behaviour would occur. In this study, perceived behavioural control is the capability to perform environmentally friendly behaviour in the workplace. Many studies (Albayrak, Aksoy, \& Caber, 2013; Mahmud \& Osman, 2010) have shown that perceived behavioural control is positively linked with pro-environmental behaviour which leads to the third hypothesis.

\section{Method}

\subsection{Procedure and Participants}

In this study, data were collected by the primary data collection method through administered questionnaires. This study was conducted at the government department and ministry in Putrajaya, Malaysia. For confidentiality, the anonymity of their identity is not revealed. The researcher used systematic sampling from the employee list in the office directory as a technique of sampling in this study. A total of 460 respondents took part in this study from a 500 set questionnaire distributed. The survey questionnaires were answered by participants are consented and voluntarily

The items were adapted from a validated instrument before administered for this study. The construct of attitude, subjective norm, perceived behaviour control and behavioural intention was measured with scales from (Blok, Wesselink, Studynka, \& Kemp, 2015; Hargreaves, 2011; Tudor et al., 2016). All the items were modified for environmental workplace intention behavioural in the Malaysian public organization culture. Measures of attitude (6 items), subjective norms (13 items), perceived behavioural control (10 items), and intention (11 items) were measured. The answers were measured on a scale from 1 (='strongly disagree') to 5 (='strongly agree'). A higher score showed that there is higher pro-environmental behaviour in the workplace. Analysis of data used regression analysis through SPSS software.

Cronbach alpha were used to ensure the internal reliability of the items (Nunnally, 1978). Minumum alpha of 0.6 would be sufficient for research recommended by Nunally (1978). The Cronbach's alpha for subjective norm was 0.909 , attitude was 0.881 , perceived behavioural control was 0.865 , and the behavioural intention scale was 0.892. As the Cronbach's alpha in this study was higher than 0.6, the constructs were therefore deemed to have satisfactory reliability.

This study involved a relatively large sample (460 respondents), and therefore the central limit theorem could be applied. Also, there is no question on the normality of the data. Two significant methods were used to determine the existence of multicollinearity among independent variables in this study. These methodologies involved the calculation of both a tolerance test and variance inflation factor (VIF) (Kleinbaumetal, 1988). The results of these analyses are presented in Table I. Data showed that none of the tolerance levels is below 0.01 and all VIF values are well below 10 .

The results indicated that there was no multicollinearity detected between the independent variables. The acceptable Durbin-Watson range is between 1.5 and 2.5. In this analysis, the Durbin-Watson value of 2.05, which is between the acceptable ranges proved that there were no correlation problems in the data used in this research. As seen in Table 1, independent variables in this study do not have any multicollinearity issue (Table 1). 
Table 1 . Test of Collinearity

\begin{tabular}{lll}
\hline Variable & Tolerance & VIF \\
\hline Attitude & 0.597 & 1.676 \\
Subjective Norms & 0.677 & 1.478 \\
Perceived Behavioural Control & 0.520 & 1.925 \\
\hline
\end{tabular}

Table 2 displays sample characteristics. The majority of the respondents were female $(60.7$ percent) and are mostly Malays, which comprised of 94.6 percent of the total respondent. According to the table, majority respondent in age group of 25-34 years old. Other than that, 69.1 percent of the respondents are made up of those who are married. Most of them also have a diploma in education and above which consists of 75 percent of the total sample.

Table 2. Sample characteristics

\begin{tabular}{|c|c|c|}
\hline & Frequency & $(\%)$ \\
\hline \multicolumn{3}{|l|}{ Gender } \\
\hline Male & 181 & 39.3 \\
\hline Female & 279 & 60.7 \\
\hline \multicolumn{3}{|l|}{ Age Group (years) } \\
\hline 24 and below & 23 & 5.0 \\
\hline 25-34 years old & 209 & 45.4 \\
\hline $35-44$ years old & 172 & 37.4 \\
\hline 45-54 years old & 39 & 8.5 \\
\hline 55 and above & 17 & 3.7 \\
\hline \multicolumn{3}{|l|}{ Ethnicity } \\
\hline Malay & 435 & 94.6 \\
\hline Chinese & 3 & 0.7 \\
\hline Indian & 5 & 1.1 \\
\hline Other & 17 & 3.7 \\
\hline \multicolumn{3}{|l|}{ Marital Status } \\
\hline Married & 318 & 69.1 \\
\hline Single & 124 & 27.0 \\
\hline Divorced & 18 & 3.9 \\
\hline \multicolumn{3}{|l|}{ Educational Level } \\
\hline SRP/PMR & 11 & 2.4 \\
\hline MCE/SPM/SPMV & 104 & 22.6 \\
\hline Diploma/ STPM & 137 & 29.8 \\
\hline Degree & 168 & 36.5 \\
\hline Postgraduate & 40 & 8.7 \\
\hline
\end{tabular}

\section{Results}

Table 3 shows the strength of the proposed relationship via MRA. After obtaining a satisfactory reliability score of the variables hence retaining the variables, three hypotheses were formulated. Using multiple regression prediction models following the guidelines established by Hair et al. (1998), individual hypotheses were tested with pro-environmental workplace intention-behaviour. 
The results, as shown in Table 3, revealed that $\mathrm{H} 1-\mathrm{H} 3$ were found to be significant and positive in the prediction model. The results provide support for hypotheses $\mathrm{H} 1-\mathrm{H} 3$, that is, the relationship between attitude $(\beta=0.271$ and $p<0.001)$, the subjective norm on environmental workplace intention behavioural $(\beta=0.151$ and $p<0.001)$, and perceived behavioural control on environmental workplace intention behavioural $(\beta=0.638$ and $p<0.001)$.

Table 3. Regression Result

\begin{tabular}{llll}
\hline Variable & $\beta$ & $t$-value & $p$-value \\
\hline Constant & 4.555 & 2.644 & 0.008 \\
Attitude & 0.271 & 3.535 & $0.000^{*}$ \\
Subjective Norm & 0.151 & 5.468 & $0.000^{*}$ \\
Perceived Behavioural Control & 0.638 & 13.335 & $0.000^{*}$ \\
\hline
\end{tabular}

Notes: Significant at: ${ }^{*} \mathrm{p}=0.001 ; \mathrm{R}^{2}=0.597$, adjusted $\mathrm{R}^{2}=0.594$; dependent variable: environmental workplace intention behavioural

\section{Discussion and Conclusion}

This study focuses on the objective of exploring the mechanism of TPB to predict the pro-environmental workplace intention behavioural among employees in public organization in Malaysia. Results portrayed that the TPB model could explain 59.7 percent of the variance in the pro-environmental workplace intention behavioural. The model was statistically significant, and this study result validates the strength of the TPB to explain pro-environmental workplace intention behavioural.

The utilization of TPB as a theoretical framework was supported in countless successful studies within the pro-environmental workplace behaviour subject (Davis, O'Callaghan, \& Knox, 2009; Gao et al., 2017; Küçükoğlu \& İbrahim Pınar, 2015; Norton, Parker, Zacher, \& Ashkanasy, 2015; Wells, Taheri, Gregory-Smith, \& Manika, 2016). The study has shown that attitude has a significant and positive effect on pro-environmental intention behavioural. As a vital factor in influencing environmental workplace intention behavioural, the increment of positive attitudes showed greater intentions to behave environmentally friendly at a workplace. Social pressure from colleague and supervisor may contribute to positive attitudes to behave environmentally friendly at the workplace. Consistent with the study of Schelly, Cross, Franzen, Hall, \& Reeve (2011) found that subjective norm was positively and significantly related to intention behavioural. This finding goes hand in hand with Chen and Tung (2010) and Zhang, Wang \& Zhou (2014) results that stated subjective norms to be a critical aspect of pro-environmental behaviour.

The finding from Blok et al. (2015) support that attitude, subjective norms and perceived behavioural control has a significant and positive effect on pro-environmental intention behavioural with attitude is the strongest factor amongst three. Norton et al., (2015) also conclude that attitude and subjective norms are the strongest individual factors that affect the pro-environmental intention behavioural and behaviour in workplace.

However in this study, perceived behavioural control was found to be the most important factor in influencing environmental workplace intention behavioural among employee in the Malaysian public organization. The study confirmed that perceived behavioural control has a significant effect as well as strongly predict pro-environmental workplace intention behavioural. Ajzen (1991) suggested that perceived behaviour control could directly affect behaviour intention by increasing the effort to achieve the objective. The review was done by Hasan, Harun and Hock (2015) and Mahmud and Osman (2010) concerning various behavioural criteria had mentioned similar findings.

\section{Managerial Implications}

It can be seen that The TPB model is capable of predicting pro-environmental workplace intention behavioural effectively among employee in public organization in Malaysia. To encourage pro-environmental workplace intention behavioural among employees, top management in government office might focus on designing an office environment and provide facilities to support employee carried out the pro-environmental behaviour in the workplace. Facilities such as recycle bin and double-sided setup photocopy or fax machine will help the employees to perceive that is it easy to be inclined in behaving more pro-environmentally at their workplace.

Secondly, to increase positive attitude change among employees, top management must design effective 
activities and regular environmental campaigns to deliver the benefits of pro-environmental behaviour and the impact to environment aiming for long-lasting attitude changes among employees. Because employees who adopt pro-environmental behaviours at work generally do influence people outside of work with their behaviours, this exposes that workplace as leverage point that is effective in creating powerful and sustainable social change (Turnbull Loverock, 2010). Thus, the result of the spill over effect of pro-environmental behaviour at work to the community and private sector will benefit the sustainability of the environment in the country.

\section{Limitation and Future Research Direction}

This study only considered original factors in TPB towards environmental intention behavioural among employee in the public sector in Malaysia. Future research should consider other elements within the Malaysian public organizational, such as such as environmental leadership (Robertson \& Carleton, 2018), green office culture, public service motivation (Azhar, 2012), facilities availability (Austin, Hatfield, Grindle, \& Bailey, 1993) corporate greening and initiatives (Lülfs \& Hahn, 2013), and home environmental behaviour (Bissing-Olson et al., 2012).

Other than that, it is important to construct valid and reliable scales to evaluate these variables specifically from the Malaysian perspective and culture in the future. The study can be strengthened by including the participant in the public organization from other geographical areas in Malaysia to represent the whole employee population in public organization. Therefore, there are more researches needed to identify and address challenges to implement pro-environmental workplace behaviour in Malaysia.

In conclusion, this research shows that only focusing on the implementation of policy and programme awareness to change the attitude may not be the most effective way of stimulating pro-environmental behaviour at work. The results of this study imply that top management also has to support and invest in facilities promoting pro-environmental behaviour to encourage employees in perceiving that pro-environmental behaviour is easy to perform since perceived behavioural control is the most influential factor in predicting the pro-environmental behaviour at a workplace in public organization.

\section{References}

Ajzen, I. (1991). The theory of planned behavior. Orgnizational Behavior and Human Decision Processes, 50, 179-211. https://doi.org/10.1016/0749-5978(91)90020-T

Albayrak, T., Aksoy, S.., \& Caber, M. (2013). The effect of environmental concern and scepticism on green purchase behaviour. Marketing Intelligence and Planning, 31(1), 27-39. https://doi.org/10.1108/02634501311292902

Austin, J., Hatfield, D. B., Grindle, A. C., \& Bailey, J. S. (1993). Increasing Recycling in Office Environments: the Effects of Specific, Informativ Cues. Journal of Applied Behavior Analysis, 2(Summer), 247-253. https://doi.org/10.1901/jaba.1993.26-247

Bissing-Olson, M. J., Iyer, A., Fielding, K. S., \& Zacher, H. (2012). Relationships between daily affect and pro-environmental behavior at work: The moderating role of pro-environmental attitude. Journal of Organizational Behavior, 34(2), 156-175. https://doi.org/10.1002/job.1788

Blok, V., Wesselink, R., Studynka, O., \& Kemp, R. (2015). Encouraging sustainability in the workplace: A survey on the pro-environmental behaviour of university employees. Journal of Cleaner Production, 106, 55-67. https://doi.org/10.1016/j.jclepro.2014.07.063

Chen, M. F., \& Tung, P. J. (2010). The moderating effect of perceived lack of facilities on consumers' recycling intentions. Environment and Behavior, 42(6), 824-844. https://doi.org/10.1177/0013916509352833

Davis, G., O’Callaghan, F., \& Knox, K. (2009). Sustainable attitudes and behaviours amongst a sample of non-academic staff. International Journal of Sustainability in Higher Education, 10(2), 136-151. https://doi.org/10.1108/14676370910945945

Etzion, D. (2007). Research on organizations and the natural environment, 1992-present: A review. Journal of Management, 33(4), 637-664. https://doi.org/10.1177/0149206307302553

Fielding, K. S., McDonald, R., \& Louis, W. R. (2008). Theory of planned behaviour, identity and intentions to engage in environmental activism. Journal of Environmental Psychology, 28(4), 318-326. https://doi.org/10.1016/j.jenvp.2008.03.003

Gao, L., Wang, S., Li, J., \& Li, H. (2017). Application of the extended theory of planned behavior to understand an individual's energy saving behavior in workplaces. Resources, Conservation and Recycling, 
127(September), 107-113. https://doi.org/10.1016/j.resconrec.2017.08.030

Graves, L. M., Sarkis, J., \& Zhu, Q. (2013). How transformational leadership and employee motivation combine to predict employee proenvironmental behaviors in China. Journal of Environmental Psychology, 35, 81-91. https://doi.org/10.1016/j.jenvp.2013.05.002

Greaves, M., Zibarras, L. D., \& Stride, C. (2013). Using the theory of planned behavior to explore environmental behavioral intentions in the workplace. Journal of Environmental Psychology, 34, 109-120. https://doi.org/10.1016/j.jenvp.2013.02.003

Hargreaves, T. (2011). Practice-ing behaviour change: Applying social practice theory to pro-environmental behaviour change. Journal of Consumer Culture, 11(1), 79-99. https://doi.org/10.1177/1469540510390500

Hasan, S. N. M. S., Harun, R., \& Hock, L. K. (2015). Application of Theory of Planned Behavior in Measuring the Behavior to Reduce Plastic Consumption Among Students at Universiti Putra Malaysia, Malaysia. Procedia Environmental Sciences, 30, 195-200. https://doi.org/10.1016/j.proenv.2015.10.035

Karim Ghani, W. A. W. A., Rusli, I. F., Biak, D. R. A., \& Idris, A. (2013). An application of the theory of planned behaviour to study the influencing factors of participation in source separation of food waste. Waste Management, 33(5), 1276-1281. https://doi.org/10.1016/j.wasman.2012.09.019

Küçükoğlu, M. T., \& İbrahim Pınar, R. (2015). Go Green at Work: Environmental Organizational Culture. $\begin{array}{lllll}\text { Modern Environmental Science and } & \text { Engineering, }\end{array}$ https://doi.org/10.15341/mese(2333-2581)/02.01.2015/004

Lokhorst, A. M., Staats, H., \& Van Iterson, J. (2015). Energy saving in office buildings: Are feedback and commitment-making useful instruments to trigger change? Human Ecology, 43(5), 759-768. https://doi.org/10.1007/s10745-015-9783-8

Lülfs, R., \& Hahn, R. (2013). Corporate greening beyond formal programs, initiatives, and systems: A conceptual model for voluntary pro-environmental behaviour of employees. European Management Review, 10(2), 83-98. https://doi.org/10.1111/emre.12008

Mahmud, S. N. D., \& Osman, K. (2010). The determinants of recycling intention-behaviour among the Malaysian school students: An application of Theory of Planned Behaviour. Procedia - Social and Behavioral Sciences, 9, 119-124. https://doi.org/10.1016/j.sbspro.2010.12.123

Maki, A., \& Rothman, A. J. (2017). Understanding environmental intentions and behaviours: The importance of considering both the behaviour setting and the type of behaviour. Journal of Social Psychology, 157(5), 517-531. https://doi.org/10.1080/00224545.2016.1215968

Norton, T. A., Parker, S. L., Zacher, H., \& Ashkanasy, N. M. (2015). Employee Green Behavior: A Theoretical Framework, Multilevel Review, and Future Research Agenda. Organization and Environment, 28(1), 103-125. https://doi.org/10.1177/1086026615575773

Nye, M., \& Hargreaves, T. (2010). Exploring the social dynamics of pro-environmental behaviour change. Journal of Industrial Ecology, 14(1), 137-149. https://doi.org/10.1111/j.1530-9290.2009.00193.x

Oreskes, N. (2005). ESSAY on Climate Change. Science, 306(January), 2004-2005. https://doi.org/10.1126/science.1103618

Paillé, P., Amara, N., \& Halilem, N. (2018). Greening the workplace through social sustainability among co-workers. Journal of Business Research, 89(June 2017), 305-312. https://doi.org/10.1016/j.jbusres.2017.12.044

Pothitou, M., Hanna, R. F., \& Chalvatzis, K. J. (2016). Environmental knowledge, pro-environmental behaviour and energy savings in households: An empirical study. Applied Energy, 184, 1217-1229. https://doi.org/10.1016/j.apenergy.2016.06.017

Ramayah, T., Lee, J. W. C., \& Mohamad, O. (2010). Green product purchase intention: Some insights from a developing country. Resources, Conservation and Recycling, 54(12), 1419-1427. https://doi.org/10.1016/j.resconrec.2010.06.007

Robertson, J. L., \& Barling, J. (2013). Greening organizations through leaders' influence on employees' pro-environmental behaviours. Journal of Organizational Behavior, 34(2), 176-194. https://doi.org/10.1002/job.1820

Robertson, J. L., \& Carleton, E. (2018). Uncovering How and When Environmental Leadership Affects 
Employees' Voluntary Pro-environmental Behavior. Journal of Leadership and Organizational Studies, 25(2), 197-210. https://doi.org/10.1177/1548051817738940

Schelly, C., Cross, J. E., Franzen, W. S., Hall, P., \& Reeve, S. (2011). Reducing energy consumption and creating a conservation culture in organizations: A case study of one public school district. Environment and Behavior, 43(3), 316-343. https://doi.org/10.1177/0013916510371754

Stern, P. C. (2000). New Environmental Theories: Toward a Coherent Theory of Environmentally Significant Behavior. Journal of Social Issues, 56(3), 407-424. https://doi.org/10.1111/0022-4537.00175

Tonglet, M., Phillips, P. S., \& Read, A. D. (2004). Using the Theory of Planned Behaviour to investigate the determinants of recycling behaviour: A case study from Brixworth, UK. Resources, Conservation and Recycling, 41(3), 191-214. https://doi.org/10.1016/j.resconrec.2003.11.001

Tudor, T. L., Barr, S. W., \& Gilg, A. W. (2016). Framework for Examining Environmental Behavior in Large Organizations A Case Study of the Cornwall National Health Service ( NHS ) in the United Kingdom. Environment and Behavior, 426-450. https://doi.org/10.1177/0013916507300664

Turnbull Loverock, D. L. (2010). Employee pro-environmental behaviours: Workplace culture as a driver for social change (pp. 1-158). https://doi.org/10.4018/978-1-4666-7294-9.ch002

Wells, V. K., Taheri, B., Gregory-Smith, D., \& Manika, D. (2016). The role of generativity and attitudes on employees home and workplace water and energy-saving behaviours. Tourism Management, 56(March), 63-74. https://doi.org/10.1016/j.tourman.2016.03.027

Young, W., Davis, M., McNeill, I. M., Malhotra, B., Russell, S., Unsworth, K., \& Clegg, C. W. (2015). Changing Behaviour: Successful Environmental Programmes in the Workplace. Business Strategy and the Environment, 24(8), 689-703. https://doi.org/10.1002/bse.1836

Zhang, Y., Wang, Z., \& Zhou, G. (2014). Determinants of employee electricity saving, The role of social benefits, personal benefits and organizational electricity saving climate. Journal of Cleaner Production, 66, 280-87.

\section{Copyrights}

Copyright for this article is retained by the author(s), with first publication rights granted to the journal.

This is an open-access article distributed under the terms and conditions of the Creative Commons Attribution license (http://creativecommons.org/licenses/by/4.0/) 